\title{
ANALYSIS OF SLOPE STABILITY IN SOFT SOIL USING HARDENING SOIL MODELING AND STRENGTHENING OF BAMBOO MATTRESS
}

\author{
${ }^{*}$ Bangun Ready ${ }^{1,}$, Krisnamurti $^{2}$, and Indra Nurtjahjaningtyas ${ }^{3}$ \\ ${ }^{1,2,3}$ Civil Engineering Departement, Jember University, Indonesia
}

*Corresponding Author, Received: 05 April 2020, Revised: 17 April 2020, Accepted: 24 April 2020

\begin{abstract}
The development of railway double track infrastructure does not always pass through section with good soil carrying capacity, some also pass through existing soil layers with soft - very soft consistency. More than 10\% of the land area in Indonesia or around 20 million hectares is soft land consisting of soft clay and peat soils. Taking into account the problems in soft clay which is quite influential in the success of infrastructure development, soil improvement must be carried out so that the infrastructure is not damaged before the planned age. Soil improvement with a bamboo mattress system provides a cost-effective and reliable solution to maintain the landfill stability and reduce the differential settlement. The Finite Element Model is a numerical way of solving problems in physical science and mathematics. This numerical method provides approximate values of unknown parameters at a number of discrete system nodal structures. The standard Hardening Soil Model (HS) is an advanced model for modeling soil behavior. However, the value of the soil stiffness is described more accurately by using three different input stiffnesses namely triaxial loading stiffness $\left(E_{50}\right)$, triaxial unloading stiffness $\left(E_{u r}\right)$ and one-way loading stiffness $\left(E_{o e d}\right)$. For certain cases, the Hardening Soil Model (HS) method is more accurate and approaches the field conditions. This can be seen from several previous studies which show that the Hardening Soil Model (HS) approach is very typical with the results of field testing. The value of the safety factor (SF) from the analysis of slope stability in soft soil using hardening soil modeling and strengthening of bamboo mattress analysis is 2.10 .
\end{abstract}

\section{Keywords: Soil improvement, Bamboo mattress, Hardening Soil Model}

\section{INTRODUCTION}

The majority of soft soils in Indonesia may consist of deposits of Holocene clay. This material is from the ejecta of volcanoes and include a potentially significant content of volcanic ash [1]. The properties of soft soils are different from those found on the coastal plains and inland, as a result of freshwater leaching [2]. also identify that the presence of volcanic-derived soils has a significant effect on the soil's properties. In many cases, the deposit is geologically very young [3]. provides a relationship between deposition rate and degree of consolidation, as shown in Fig. 1. The average degrees of consolidation for deltaic clays in Southeast Asia may be from 20-100\% depending on their location. For sediments in Indonesia, for instance, the degree of consolidation is predicted (from Fig. 1) to be $70-80 \%$. This means that the soft clays in a marine environment are underconsolidated.

One of the main problems of embankment activities on soft soils is the occurrence of landslides. There are still difficulties often faced on road constructions that are built on soft soil in swampy areas, even more so if there is no material for strengthener purposes on the road itself [4]. Backfills materials often drowned into the softer ground soil since it is not strong enough to bear the embankment soil [5]. Basically, soil improvement has a general objective, namely to increase the bearing capacity and shear strength of the soil, increase soil modulus, reduce soil compressibility, control soil stability (shrinkage and swelling), improve the quality of materials for construction materials, and minimize the effect of damage to work in the surrounding area. One of the treatments for this problem is to gradually accumulate soil and increase the carrying capacity of the soil using bamboo mattresses [6].

The bamboo piles are generally provided with a mattress made of woven bamboo or geotextile. In this case, the main role of the piles and the mattress is to reinforce the soft soil and form a cluster to support the load of the embankment and to reduce differential settlement; thus, this minimizes damage to the road pavement and increases stability during construction.

In practice, this system works very well. The reduction of settlement does not significantly depend on the spacing of the bamboo piles and, based on the full-scale experimental study in Jakarta, it is reported that compared to untreated ground, the use of a bamboo pile-raft system reduced settlement of the soft ground to $30 \%$ [7]. 
The calculation analysis above will be carried out with Hardening Soil (HS) model approach. The popularity of the elasto-plastic Hardening Soil (HS) model is based on simple parameter identification from standard testing and empirical formulas. The HS model is implemented in many commercial FE codes designed to analyse geotechnical problems [8]. The basic version of the elasto-plastic Hardening Soil (HS) model was developed by Schanz, Vermeer, and Bonnier [9] and implemented into the Plaxis FE code [10]. The main framework of the HS model may be explained by drawing the contours of yield surfaces on the plane of Roscoe's stress invariants p-q. It is shown in Fig. 2. The Mohr-Coulomb shear strength criterion limits shear stress levels, whereas the volumetric and pre-failure deviatoric hardening is controlled by two yield surfaces. The HS model is entirely isotropic in both the elastic and elasto-plastic ranges. Hence, no inherent and stress induced anisotropy is available contrary to the experimental evidence especially in fine grained deposits, e.g. [11, 12].

In the initial HS version, the hypoelastic stress-strain relation is used within the elastic range with the stress-dependent Young's modulus $\mathrm{E}_{\mathrm{ur}}\left(\mathrm{E}_{\mathrm{ur}}^{\mathrm{ref}}, \sigma\right)$ via power law and constant Poisson's ratio $v_{u r}$. In the HSS version, the small strain stiffness depends on both stress and accumulated shear strain, while in the hypoelastic relation the actual reference shear modulus $\mathrm{G}_{\mathrm{t}}^{\text {ref }}$ changes between the values $G_{\text {ur }}^{\text {ref }}$ and $G_{0}^{\text {ref }}$

\section{GENERAL PROJECT INFORMATION}

\subsection{Description of the Experimental Site}

The experimental site is located at the railway cross-section KM 103+00 - KM 107+100 between the Jombang city and the Madiun city, East Java,

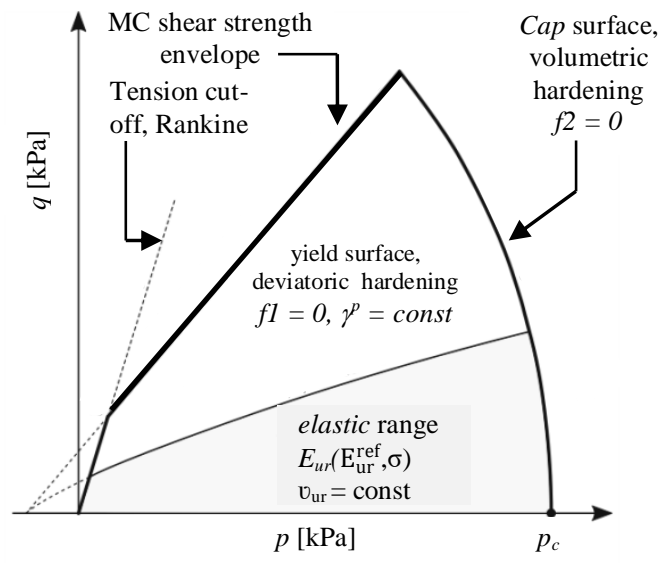

Fig 2. Yield surfaces and elastic range in the basic HS model [8].

Indonesia. The embankment is $3.5 \mathrm{~m}$ high, with a crown width of $6.3 \mathrm{~m}$. Details about installing Bamboo mattress shown in Fig 3 and The construction of the embankment is described by seven sublayers (0.5 m high each) and with respective side slopes shown in Fig. 4 and applied in 90 days. The filling material consists mainly of plain fill with a cohesion of $7 \mathrm{kPa}$, a friction angle of $40^{\circ}$, and an average unit weight of $17 \mathrm{kN} / \mathrm{m}^{3}$.

\subsection{Method of Construction}

Method of installation of bamboo piles varies depending on the available equipment. For a bamboo pile of 3- $4 \mathrm{~m}$ in length, a backhoe can be used to push the pile into soft ground. In certain areas where heavy equipment is not available, a drop hammer is common, as this technology is often locally available. The hammer weight is usually in the range of 300-700 kg [13]. Figure 57 shows the sequence of construction of an embankment on soft soil with a bamboo pile-raft system for a railway project.

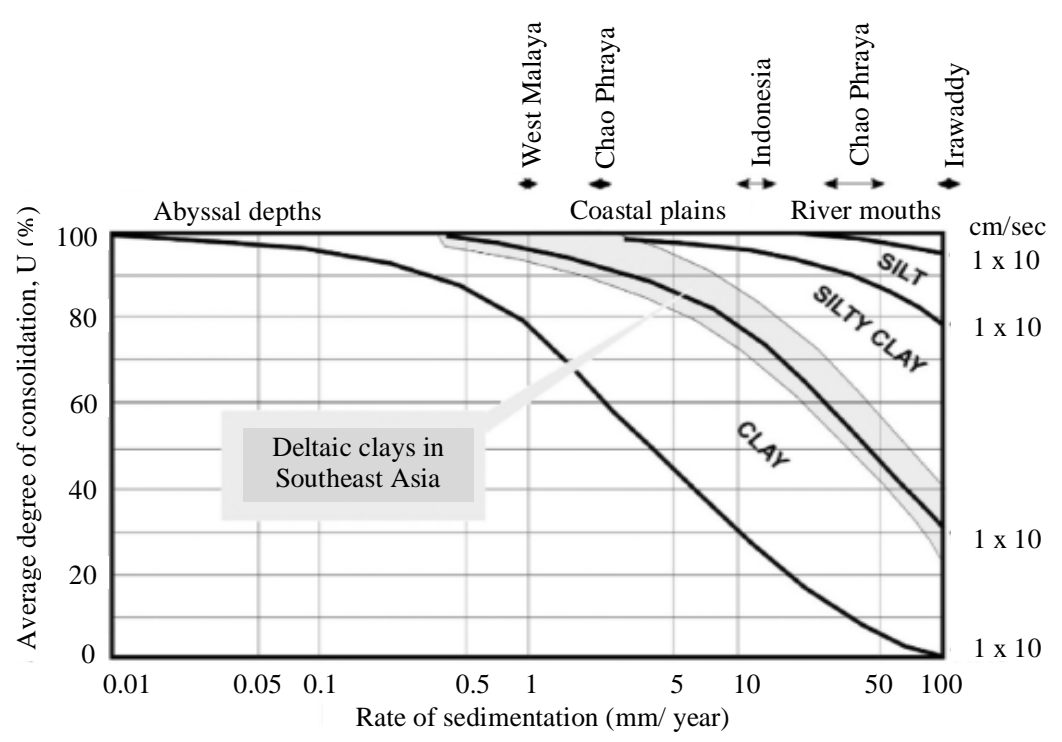

Fig 1. Relationship between rate of sedimentation and degree of consolidation [3] 
The bamboo piles were driven and bamboo mattresses bound in two layers, as shown in Fig. 6 were then laid on the ground surface before spreading the fill material. The fill placement was followed by compaction, as shown in Fig. 7 This system was successfully applied.

Bamboo piles 3 pieces (dia. $10 \mathrm{~cm})$

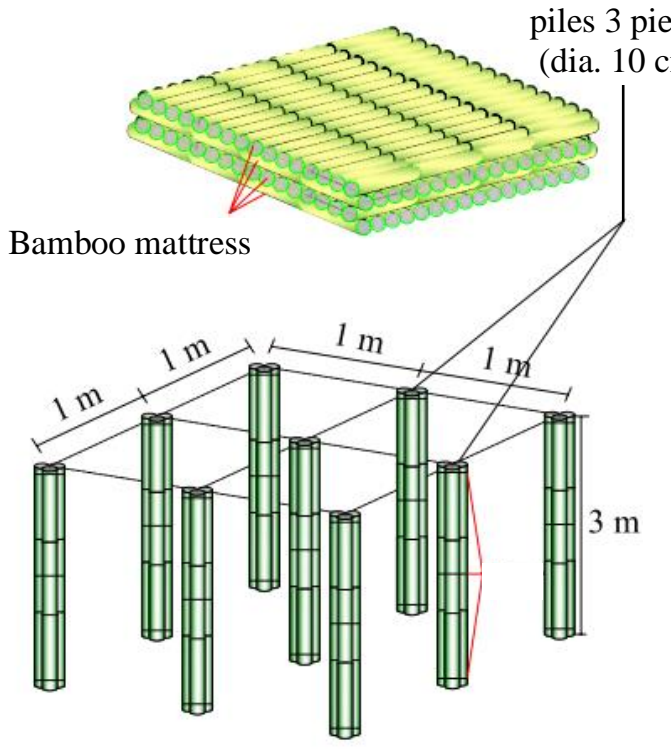

Fig 3. Bamboo mattress installing [24]

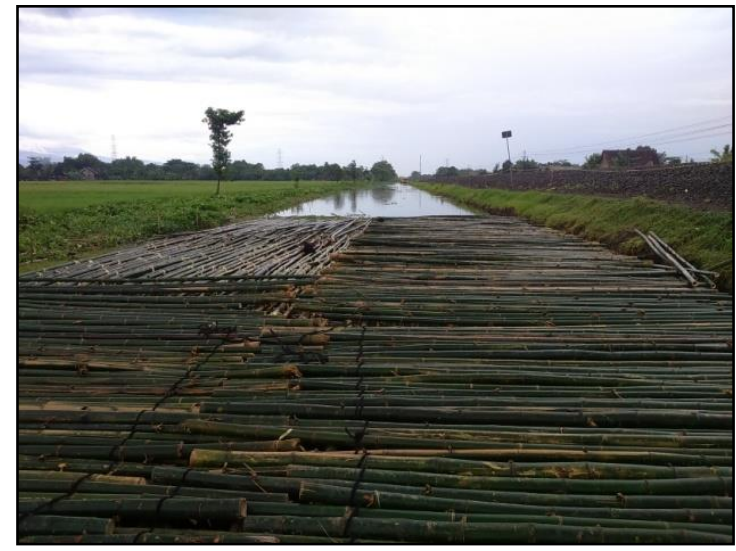

Fig 6. Installation of bamboo mattresses [14]

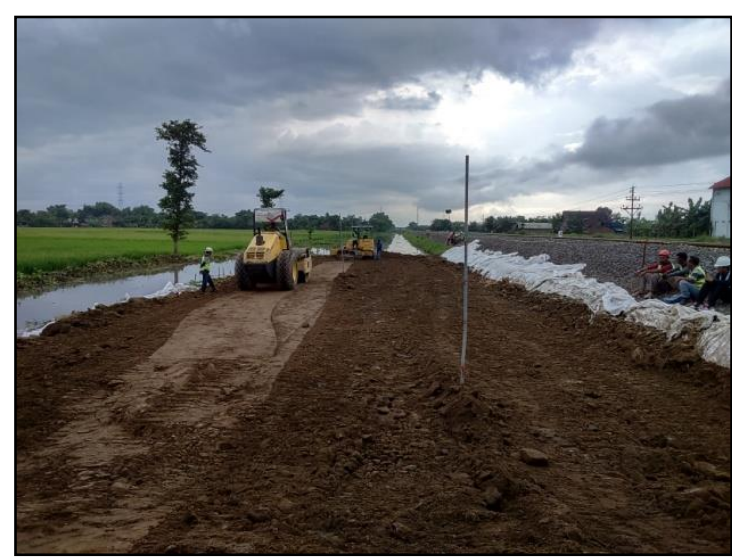

Fig 7. Spreading the fill material and compaction [14]

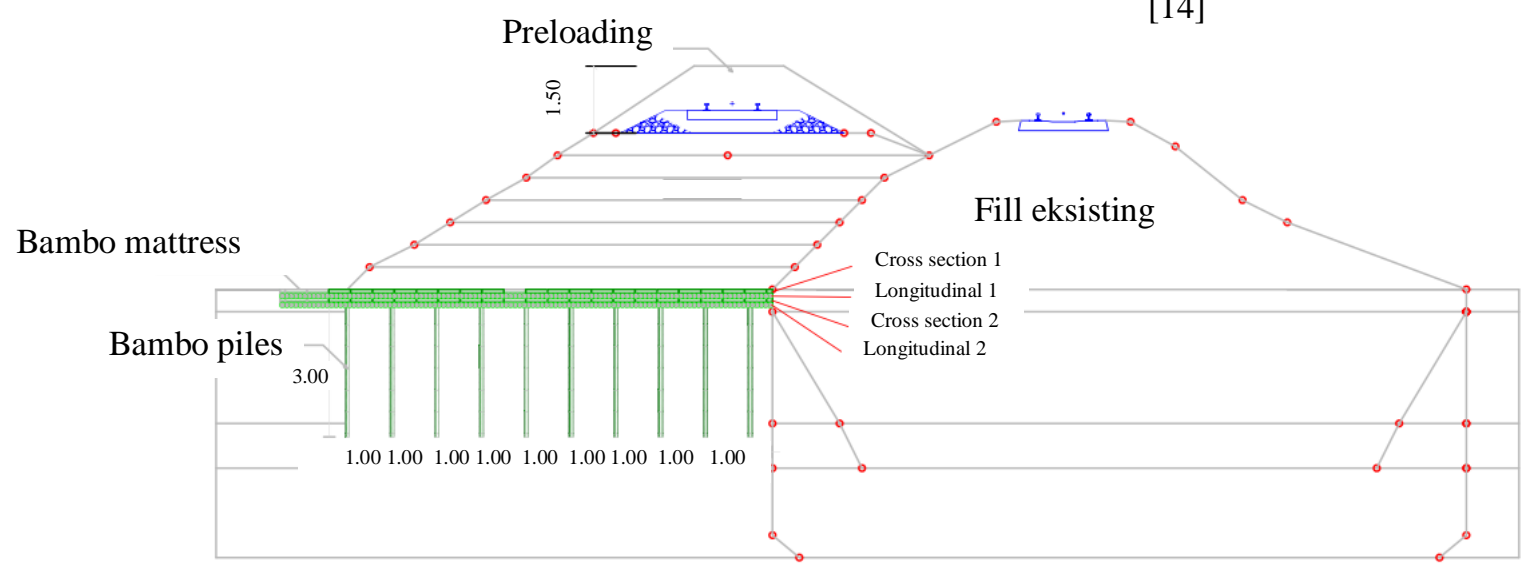

Fig 4. Typical of railway cross-section KM 103+00 - KM 107+100 [14]

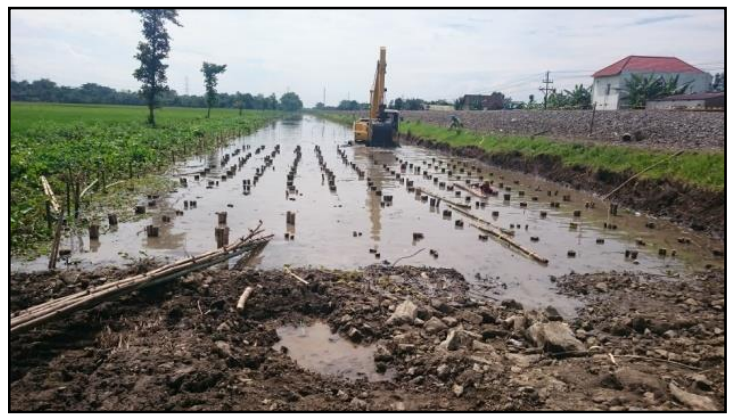

Fig 5. Driving bamboo piles [14]
Geosynthetic reinforcement is sometimes required to provide additional stability in the construction of embankment on soft soil. However, it can only help stability to a certain extent. Geosynthetic reinforcement cannot reduce pore water pressure during fill placement and, thus, settlement is still a big issue [14]. Figure 8 shows the Geosynthetic reinforcement applied. 


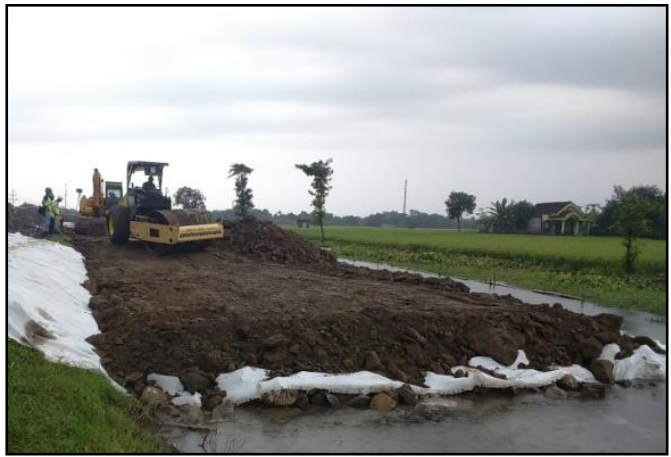

Fig 8. The Geosynthetic reinforcement applied [14]

\section{APPROACHES FOR ANALYSIS}

\subsection{Conservative Methods}

Consideration in the stability of embankment on soft soil is most critical during construction. This is due to low permeability of the soft clay, which does not allow drainage and consolidation during loading, so that very little or no shearing resistance of the foundation soil may be developed. However, after consolidation takes place, the resulting shearing resistance in the foundation soil will completely remove the need for reinforcement. This situation is explained in Fig. 9.

The use of piles as a foundation improves stability and reduces settlement. It also enables an embankment to be constructed to any height at an unrestricted rate [15]. Conventionally, the bearing capacity of the pile should be sufficient to carry the weight of the fill above it with an equivalent area of $s^{2}$, where $\mathrm{s}$ is the distance between piles. Figure 10. illustrates the method. This approach is too conservative because, in practice, the mattress or pile cap also carries the embankment load and acts interactively with the pile.

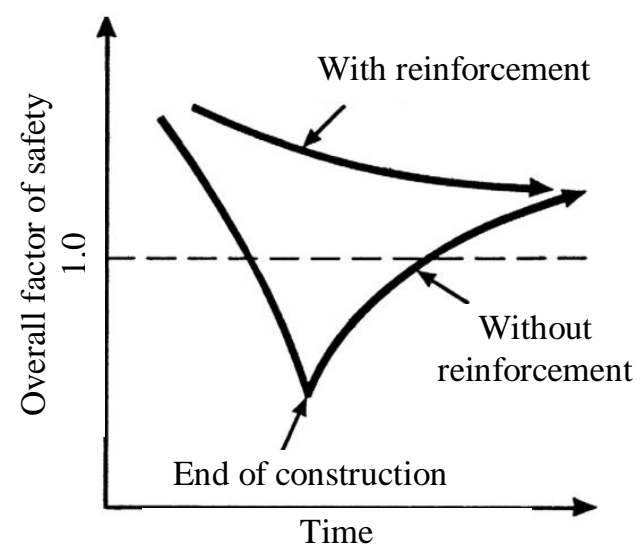

Fig 9. Influence of reinforcement on stability of embankment on soft soils [16].
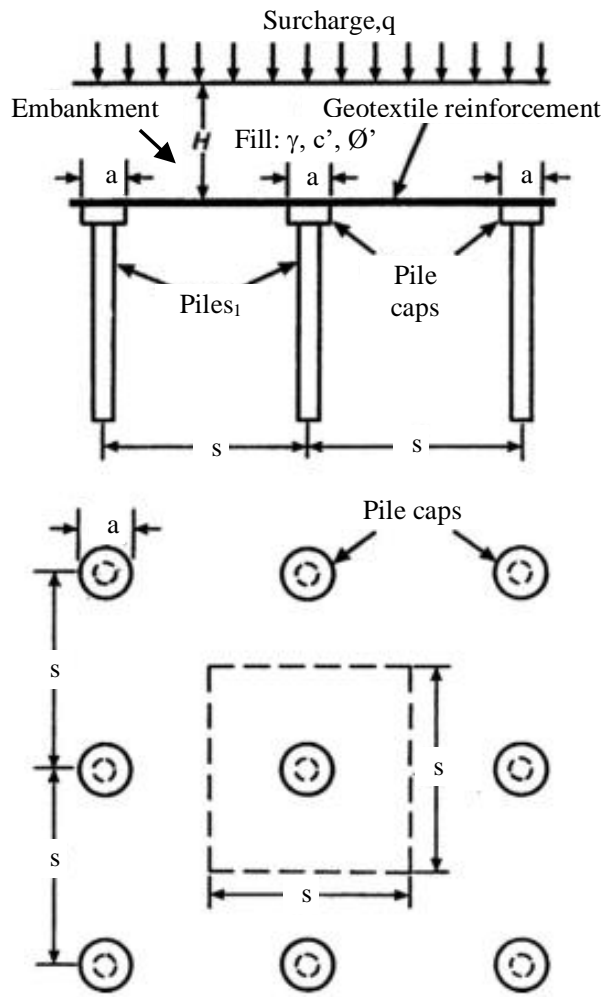

where:

Maximum pile spacing $\mathrm{s}=\sqrt{\frac{\boldsymbol{F}_{p}}{\gamma_{e} \boldsymbol{H}}}$

$F_{p}$ is the allowable load capacity of the pile,

$\gamma_{e}=(\gamma+q / H)$ is the effective unit weight of

the embankment fill. $\gamma_{e}$ takes into

account the effect of surcharge loading on top of the embankment as well as actual unit weight of the fill.

$H$ is the height of the embankment

Fig 10. Determination of maximum pile spacing

$$
\text { [15]. }
$$

\subsection{Review of the Basic HS Model}

The first small strain stiffness extension to the HS formulation was proposed Benz and coworkers [17, 18], and the new model is called Hardening Soil Small (HSS). The new formulation introduces a special algorithm of controlling the current hypoelastic stiffness within the elastic range of the basic HS model. Additional parameters can be obtained from extended standard tests or empirical formulas.

The basic HS model belongs to the class of multi-surface elasto-plastic models. The deviatoric and the volumetric cap yield surfaces, with the corresponding plastic flow rules, and hardening laws, are the two major plastic mechanisms introduced to represent the nonlinear soil behaviour. The ultimate limit states are controlled by the Mohr-Coulomb and Rankine strength criteria. The main model equations and theoretical 
assumptions are systematized in [9]. Since the HS model is implemented in several FE codes, so this only emphasize the main characteristic aspects of the formulation in the currently developed version of ZSoil FE code [19]. This version of the basic HS model is refined to account for the small strain stiffness and used in the calculations presented in the article.

The extended HSS model is also implemented in commercial geotechnical FE codes available for researchers and practitioners. However, the HSS formulation exhibits serious fault known in the literature as overshooting, i.e. uncontrolled reset of the loading memory and regain of high initial stiffness after tiny unloading-reloading cycles. It is illustrated schematically in Fig. 11. The overshooting problem in the HSS model is critically reviewed in details in [20]. Small loading reversal continued by reloading causes unexpected irregularity in the hysteresis.

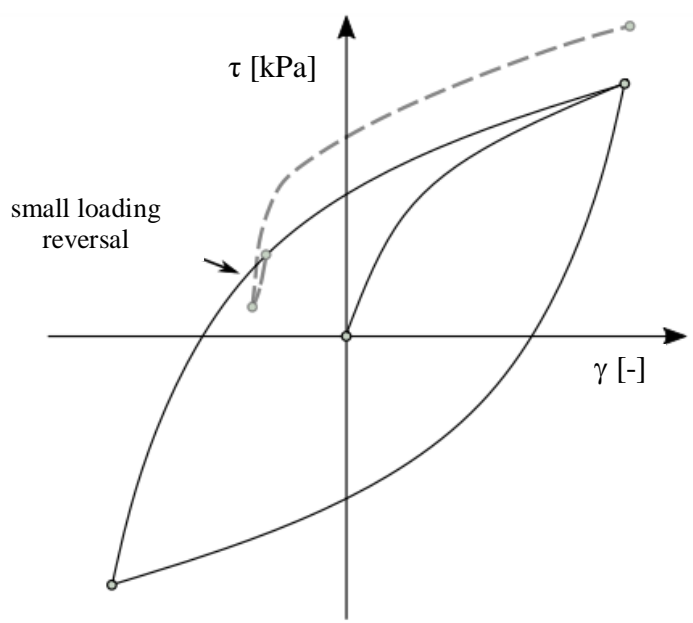

Fig 12. Example of overshooting as a fault in the modelling of hysteretic behaviour during cyclic shearing [20].

\subsubsection{Deviatoric Plastic Mechanism}

The yield surface controlling the deviatoric hardening mechanism is expressed as follows [9]:

$f 1=\frac{q_{a}}{E_{50}} \frac{\sigma_{1-} \sigma_{3}}{q_{a}-\sigma_{1-} \sigma_{3}}-2 \frac{\sigma_{1-} \sigma_{3}}{E_{u r}}-\gamma=0$ for

$$
\mathrm{q}<\mathrm{q}_{\mathrm{f}}
$$

where the asymptotic and ultimate deviatoric stresses $\mathrm{q}_{\mathrm{a}}, \mathrm{q}_{\mathrm{f}}$ are defined as:

$q_{f}=\frac{2 \sin (\varnothing)}{1-\sin (\emptyset)}-\left(\sigma_{3}+c \cot \emptyset\right)$,

$q_{a}=\frac{q_{f}}{R_{f}}$, and $\mathrm{Rf}<1.0$ is the failure ratio. We also assume that the minimum initial value of the hardening parameter $\gamma_{\mathbf{0}}^{P} \geq 10^{-6}$ and $\sigma_{1} \geq \sigma_{2} \geq \sigma_{3}$.

The plastic flow rule is derived from the following plastic potential function:

$g_{1}=\frac{\sigma_{1-} \sigma_{3}}{2}-\frac{\sigma_{1+} \sigma_{3}}{2} \sin \psi_{m}$

The mobilized dilatacy angle $\psi_{\mathrm{m}}$ is defined after Rowe [21] as:

$\sin \psi_{m}=D \frac{\sin \emptyset_{m}-\sin \emptyset_{c s}}{1-\sin \emptyset_{m} \sin \emptyset_{c s}}$,

where mobilized and critical state friction angles $\emptyset_{\mathrm{m}}, \emptyset_{\mathrm{cs}}$ are calculated from:

$\sin \emptyset_{m}=\frac{\sigma_{1-} \sigma_{3}}{\sigma_{1}+\sigma_{3}+2 c \cot \emptyset}$

$\sin \emptyset_{\mathrm{cs}}=\frac{\sin \emptyset-\sin \psi}{1-\sin \emptyset \sin \psi}$

It is worth noting that $\mathrm{D}=1$ in the reference Rowe's formula [20]. In general, when $\sin \emptyset_{\mathrm{m}}<$ $\sin \varnothing_{\text {cs }}$, the contractancy cut-off condition is assumed and $\sin \psi_{\mathrm{m}}$ value is scaled by the parameter $\mathrm{D} \leq 1.0$. In the basic HS model $\mathrm{D}=0$, whereas in the extended version with small strain stiffness refinement $\mathrm{D} \approx 0.25$.

The hardening law in the deviatoric mechanism is given by:

$d \gamma^{P}=d \lambda_{1}\left(\frac{\partial g_{1}}{\partial \sigma_{1}}-\frac{\partial g_{1}}{\partial \sigma_{3}}\right)=d \lambda_{1}$,

\subsubsection{Volumetric Plastic Mechanism}

The smooth cap yield surface is described by the following equation:

$f_{2}=\frac{q^{2}}{M^{2} r^{2}(\theta)}+p^{2}-\mathrm{p}_{0}^{2}=0$,

In the above expression $r(\theta)$ is defined after van Ekelen's [22] formula:

$r(\theta)=\left(\frac{1-\alpha \sin (3 \theta)}{1-\alpha}\right)^{n}$,

where

$\sin (3 \theta)=-\frac{3 \sqrt{3}}{2} \frac{J_{3}}{\mathrm{~J}_{2}^{\frac{3}{2}}}$

$\alpha=\frac{k \frac{1}{n}-1}{k \frac{1}{n}+1}$

$k=\frac{3-\sin \varnothing}{3+\sin \varnothing}$ 
The power exponent $\mathrm{n}=-0.229$ and the parameter $\alpha \leq 0.7925$.

A non-associated plastic flow rule is derived from the following potential function:

$g_{2}=\frac{q^{2}}{M^{2}}+p^{2}$

The above form is crucial for the efficient implementation scheme in which the stress return algorithm is executed in the principal stress space. It is worth noting that the plastic potential is obtained from the yield function $\mathrm{f}_{2}$ (Eq. 9) by fixing $r(\theta)=1$. One can set the $r(\theta)$ to any fixed value in

the range k...1 (Eq. 13)

The volumetric hardening law is expressed in the following form:

$d p_{c}=H\left(\frac{p_{c}}{p_{\text {ref }}}\right)^{m} d \varepsilon_{v 2}^{P}$,

$d \varepsilon_{v 2}^{P}=d \lambda_{2} \frac{\partial g_{2}}{\partial p}$

where the volumetric plastic strain increment $d \varepsilon_{v 2}^{P}$ is generated entirely by the cap mechanism. The internal model parameters $\mathrm{M}$ and $\mathrm{H}$ are derived taking into account the assumed $K_{0}^{N C}$ value and the reference tangent oedometric modulus $E_{\text {oed }}^{\text {ref }}$ defined at a given vertical stress assuming the normal consolidation.

\subsubsection{Stiffness Barotropy}

In the basic HS model [9], the unloadingreloading $\mathrm{E}_{\mathrm{ur}}$ and secant $\mathrm{E}_{50}$ stiffness moduli are stress dependent by the following power laws and the corresponding empirical barotropy function $\mathrm{f}_{\sigma}$ :

$E_{u r}(\sigma)=E_{u r}^{r e f} f_{\sigma}(\sigma)$,

$E_{50}(\sigma)=E_{50}^{r e f} f_{\sigma}(\sigma)$,

$f_{\sigma}(\sigma),=\left(\frac{\sigma_{3}+c \cot \emptyset}{P_{r e f}+c \cot \emptyset}\right)^{m}$.

However, the above form exhibits certain drawbacks, e.g. when deep excavations or highly overconsolidated soil layers are analysed. In such conditions, horizontal stresses are usually larger than the vertical ones. Therefore, we prefer to use the following barotropy function based on the mean effective stress:

$f_{\sigma}(\sigma),=\left(\frac{P}{P_{\text {ref }}}\right)^{m}$.

In both cases, a certain cut-off condition has to be applied for the minimum value of stress invariants $\sigma_{3}$ or $p$ to avoid too low stiffness modul.

\section{THE FACTOR OF SAFETY CALCULATION}

The factor of safety (FS) is commonly used to quantify slope stability in geotechnical engineering. In this study, finite element analysis was used to obtain the vertical settlement and the embankment factor of safety that happens on the slope. Embankments were modeled using Plaxis 2D, as shown in Fig. 13. The train load was applied on the embankment as a distributed load of 43.75 $\mathrm{kN} / \mathrm{m}^{2}$. This program including construction sequence simulation [4]. Material data used for the full-scale model of Embankment summarized in Tables 1. Hardening Soil (HS) model was used in this analysis.

\section{RESULTS AND DISSCUSSIONS}

No large settlement for the foundation soil (Bamboo mattress) in any of the analytical conditions occurred, this is due to the contribution of the Bamboo mattress. Figure 14 shows the typical of vertical displacement embankment with final construction conditions, and Figure 15 shows the value of vertical displacement. Whereas, the field observations show that vertical displacement embankment is 0.02 meters.

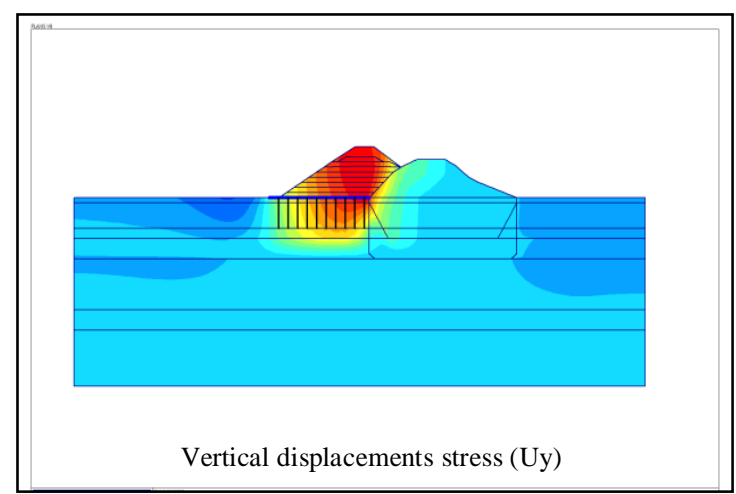

Fig 14. Typical of vertical displacement stress

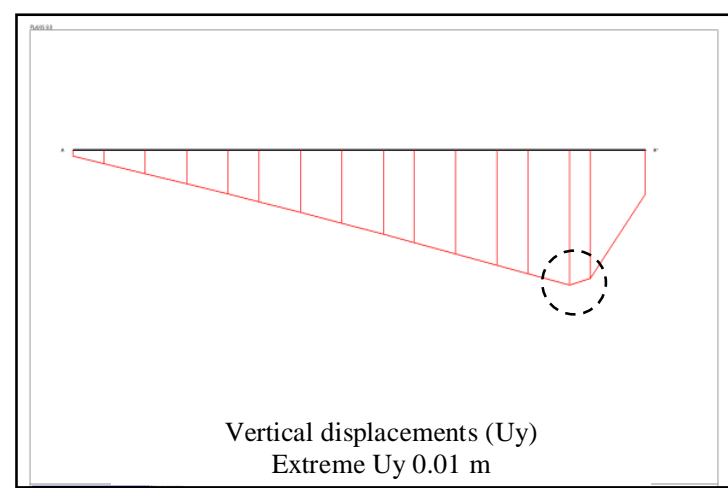

Fig 15. The value of vertical displacement is 0.01 meters 


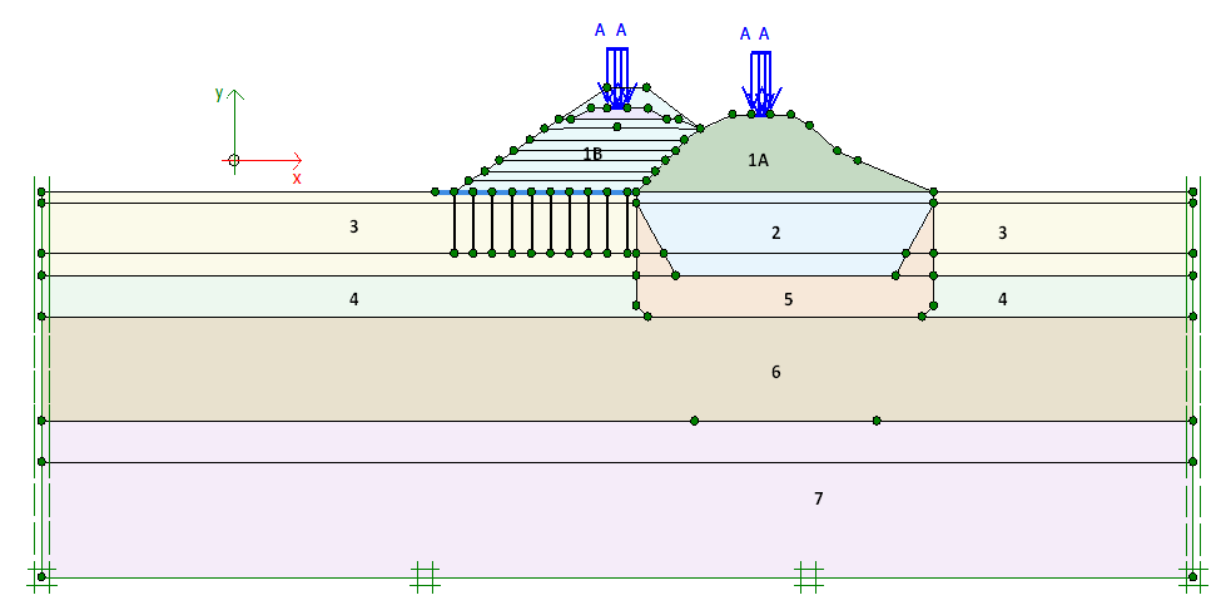

Fig 13. Finite element model for the embankment

Table 1. Full scale soil data

\begin{tabular}{|c|c|c|c|c|c|c|c|c|c|c|}
\hline Material & Notation & Model & $\begin{array}{c}\gamma \\
(k N / m 3) \\
\end{array}$ & $\begin{array}{c}\mathrm{cu} \\
(\mathrm{kN} / \mathrm{m} 2)\end{array}$ & $\begin{array}{l}\phi \\
\left({ }^{\circ}\right)\end{array}$ & $\begin{array}{c}E_{\mathrm{ur}}=E \\
(\mathrm{kN} / \mathrm{m} 2 / \mathrm{m})\end{array}$ & $\begin{array}{c}\mathbf{E}_{50} \\
(\mathrm{kN} / \mathrm{m} 2 / \mathrm{m})\end{array}$ & $\begin{array}{c}\mathrm{E}_{\text {Oed }} \\
(\mathrm{kN} / \mathrm{m} 2 / \mathrm{m})\end{array}$ & $v$ & $\begin{array}{c}\mathrm{K}_{0}^{\mathrm{NC}} \\
(1-\sin \phi)\end{array}$ \\
\hline Selected agregate & $1 \mathrm{a}$ & HS & 17 & 5 & 45 & 40000 & 13333.33 & 13333.33 & 0.3 & 0.29 \\
\hline Gravelly sand & $1 \mathrm{~b}$ & HS & 17 & 7 & 40 & 24000 & 8000 & 8000 & 0.3 & 0.36 \\
\hline Limestone agregate & 2 & HS & 18 & 20 & 45 & 40000 & 13333.33 & 13333.33 & 0.3 & 0.29 \\
\hline Silty clay & 3 & HS & 14 & 35 & 2 & 9000 & 3000 & 3000 & 0.35 & 0.97 \\
\hline Clayey sand & 4 & HS & 15.5 & 3 & 10 & 2000 & 666.67 & 666.67 & 0.35 & 0.83 \\
\hline Clayey sand & 5 & HS & 16 & 5 & 15 & 6000 & 2000 & 2000 & 0.33 & 0.74 \\
\hline Silty clay & 6 & HS & 16.5 & 100 & 5 & 24000 & 8000 & 8000 & 0.33 & 0.91 \\
\hline Sandy clay & 7 & HS & 17 & 130 & 5 & 40000 & 13333.33 & 13333.33 & 0.3 & 0.91 \\
\hline
\end{tabular}

The value of FS embankment is 2.10. Changes in the value of the FS along with the stages of the implementation of embankment, as shown in Fig. 16 about changes of FS.

Figure 17 shows the deformation stress of Embankment. Whereas, the minimum FS limit based on geotechnical code for slopes is 1.50. That is, the embankment is both reviewed based on the implementation stage and the material used is safe.

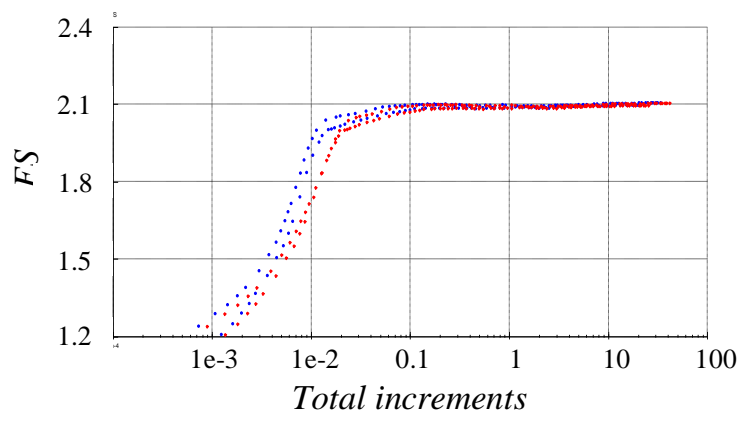

Fig 16. Changes of FS.

For certain cases, the Hardening Soil (HS) model is more accurate and approaches the field conditions. This can be seen from several previous studies which show that the Hardening Soil (HS) model approach is very typical with the results of field testing [23], as shown in Fig. 18 the result of experiment and HS calculation.

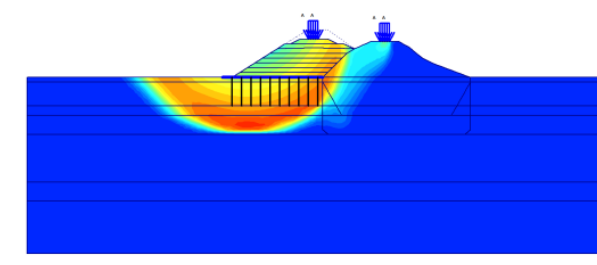

Total displacements stress (Utot)

Fig 17. The deformation stress of Embankment

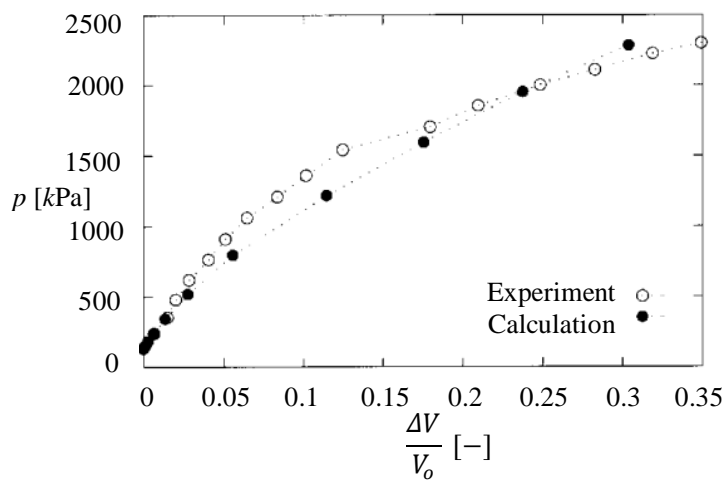

Fig 18. The result of experiment and HS calculation [23] 


\section{CONCLUSIONS}

This work focuses on the study of Hardening Soil (HS) model analysis approaches and actual conditions in the field. The results of the analysis have the same typical results of the field investigation. The following conclusions can be drawn:

a. The vertical displacement or settlement based on the results of the analysis using the Hardening Soil (HS) method is 0.01 meters while the field observation data is 0.02 meters. The consolidation time based on the Finite Element analysis is 90 days.

b. The factor of safety (FS) of embankment with HS approach is 2.10 .

c. The use of bamboo mattresses greatly contributes to increasing the carrying capacity of soils.

\section{ACKNOWLEDGMENTS}

We would like to thank PT.CHEIL JEDANG INDONESIA - PASURUAN PLANT for study support and research grant. Next, the data for this paper is provided by Mr. Helmy Darjanto and Mr. Farid Maruf.

\section{REFERENCES}

[1] Barry, A.J., Rachlan, A., Embankment on soft soils in North Java. Embankments on soft soils. In: Proceedings of the Preconference Volume, International Conference on In situ Measurement of Soil Properties and Case Histories, Bali, Indonesia, 2001.

[2] Younger, J.S., Ground improvement options for highways in Indonesia. In: Proceedings of the Short Course and Seminar on Ground Improvement, Application to Indonesia Soft Soils, Universitas Kristen Indonesia and Asian Institute of Technology in Cooperation with Himpunan Ahli Tanah Indonesia, Jakarta, August 23-26, 1988, pp. S3/i-S3/32.

[3] Cox, J.B., The distribution and formation of recent sediments in South East Asia. In: Proceedings of the Second South East Asia Conference on Soil Engineering, 1970, pp. 30-47.

[4] Muhammad, A, Indrasurya, B.M, Noor, E.M, and Yulian, F.A., Road Embankment FullScale Investigation On Soft Soil With Geotextile Stabilization. International Journal of GEOMATE, July, 2020, Vol.19, Issue 71, 2020, pp. 145 - 152 .

[5] Hardiyatmo, H.C., Geosynthetic for Highway Engineering-Planning and Application, 2013.

[6] Raharjo.P.P., Use of Bamboo and Bakau Piles For Soil Improement and Application of a Pile-Raft System For Embankment
Construction On Peat and Soft Soil. Parahyangan Catholic University, Bandung, Indonesia, 2015.

[7] Rahadian, H., Prabudi, S., Chandra, Y.P., Perilaku Uji Timbunan di atas Tanah Lunak Menggunakan Kombinasi Cerucuk Kayu dan Stabilitas Cleanset di Penjaringan Jakarta (The behaviour of embankment on soft soils reinforced by timber raft and stabilized by clean set at Penjaringan, Jakarta). In: Proceedings of the Pertemuan Ilmiah Tahunan IV, Hatti, November 22-23, 2000.

[8] Marcin, C. and Andrzej, T., Refinement of the Hardening Soil model within the small strain range. Acta Geotechnica. https://doi.org/10.1007/s11440-020-00945-5, 2020.

[9] Schanz, T. Vermeer, P.A., and Bonnier, P.G., The Hardening Soil model: formulation and verification. In: Beyond 2000 in computational geotechnics-10 years of plaxis. Rotterdam, Balkema, 1999, pp 1-16.

[10] Brinkgreve, R.B.J., Kumarswamy, S., Swolfs W.M., Zampich, L., and Ragi Manoj. N., Plaxis finite element code for soil and rock analyses. Plaxis BV, Bentley Systems, Incorporated, Philadelphia, 2019.

[11]Lings, M.L., Pennington, D.S., and Nash D.F.T., Anisotropic stiffness parameters and their measurement in a stiff natural clay. Ge'otechnique 50(2), 2000, pp 109-125 27.

[12] Mašin, D. and Rott, J., Small strain stiffness anisotropy of natural sedimentary clays: review and a model. Acta Geotech 9(2), 2014, pp 299-312.

[13]Broms, B.B., and Wong, I.H., Embankment piles. Soil improvement methods. In: Proceedings of the Third International Geotechnical Seminar, Nanyang Technological Institute, Singapore, November, 1985, pp 27-29.

[14]Darjanto, h. and Ma'ruf, M. F., Report of KJGJM-1 Package. Soft soil reinforcement purposes with bamboo cerucuk mats on the cover of the double track railway jombang Surabaya-kertosono. Advanced geotechnical engineer, 2016.

[15]Lawson, C.R., Applied Ground Improvement Techniques. Workshop Applied Ground Improvement Techniques, Southeast Asian Geotechnical Society (SEAGS), Asian Institute of Technology, Bangkok, 1992.

[16] Jewell, R.A., The Mechanics of Reinforced Embankments on Soft Soils. Report No. OUEL 1694/87, University of Oxford, 1987.

[17] Benz, T., Small-strain stiffness of soils and its numerical consequences. Ph.D. thesis, University of Stuttgart, 2007. 
[18]Benz, T. Vermeer, P. and Schwab, R., A small-strain overlay model. Int J Numer Anal Methods Geomech 33, 2009, pp 25-44

[19]ZACE Services Ltd., Software Engineering, Lausanne, Switzerland, ZSOIL ${ }^{\circledR}$.User manual ZSoil.PC v2020. Soil, Rock and Structural Mechanics in dry or partially saturated media, 2020.

[20] Niemunis, A. and Cudny, M., Discussion on "Dynamic soilstructure interaction: a threedimensional numerical approach and its application to the Lotung case study', Poor performance of the HSS model. Comput Geotech 98, 2018, pp 243-245.

[21] Rowe, P., The stress-dilatancy relation for static equilibrium of an assembly of particles in contact. Proc R Soc Lond 269, 1962, pp $500-527$
[22] Eekelen, H.A.M., Isotropic yield surfaces in three dimensions for use in soil mechanics. Int J Numer Anal Methods Geomech 4, 1980, pp 89-101.

[23] Tom, S. Pieter, A. Vermeer, and P. G. Bonnier, The hardening soil model: Formulation and verification. DOI:10.1201/9781315138206-27, 2019.

[24] Masyhur, I., Bamboo Pile-Mattress System As An Alternative Of Soft Ground Improvement For Coastal Embankment In Indonesia, Workshop HATTI, 2018.

Copyright (C) Int. J. of GEOMATE. All rights reserved, including the making of copies unless permission is obtained from the copyright proprietors. 